\title{
Polyethylene fiber post modification with vital pulp therapy in a traumatized immature incisor using Biodentine: A four year follow-up case report
}

\author{
Alem Cosgun ${ }^{1} \bowtie$, (D) Halenur Altan ${ }^{2}$
}

\section{Highlights}

It is quite difficult to determine the correct treatment procedure to success in the treatment of dental trauma cases in the form of crown fractures in teeth with immature root formation.

\section{Assistant Professor \\ Tokat Gaziosmanpaşa University, Faculty of Dentistry, Department of Pediatric Dentistry, \\ Tokat, Turkey \\ 2 Associate Professor \\ Tokat Gaziosmanpaşa University, Faculty of Dentistry, Department of Pediatric Dentistry, \\ Tokat, Turkey}

This case report presents the treatment of the complicated crown fracture with the open apex of the tooth of a delayed admitted patient, with modified polyethylene fiber post.
This novel treatment type may promise favorable outcome and can be used in such cases.

\section{Abstract}

In this case, it was aimed to restore a traumatized permanent incisor with open apex using a modified polyethylene fiber post after amputation as well as to present a four-year long term follow-up. A healthy 10 -year-old boy was referred with a complaint of pain caused by tooth number 11 . The patient fell and broke his upper incisor ten days ago and no treatment was done before. Total amputation was carried out after clinical and radiological examination. The exposed root pulp was covered with Biodentine ${ }^{T M}$ (Septodent, SaintMaur-Fosses Codex, France). Glass-ionomer cement (Fuji IX extra, GC Corp., Tokyo, Japan) was placed on the Biodentine ${ }^{\mathrm{TM}}$, and after a 3-month followup, polyethylene fiber post (Ribbond, Seattle, WA, USA) was placed in the crown since healing was observed in the relevant tooth. The restoration was completed with composite resin (Clearfil Majesty Esthetic Kuraray, Osaka, Japan). Four years later, radiographic examination revealed completed root formation and complete root obliteration. Clinical examination revealed favorable esthetic and functional outcome. Traditional treatments can be modified in order to obtain long term clinical success. Polyethylene fiber post can be used as an alternative method to root canal therapy in complicated crown fractures in teeth with immature root formation due to the advantages such as the possibility of modification according to the crown, aesthetics, easy application, and supporting the vitality of the tooth.

\section{Correspondence:}

Tokat Gaziosmanpaşa University, Faculty of Dentistry, Department of Pediatric

Dentistry, Tokat, Turkey

E-mail address:

alemcosgun@hotmail.com

Keywords: Biodentine; Pulpotomy; Ribbond; Tooth Fractures 


\section{INTRODUCTION}

Thalassemia is a single gene disorder that is caused by any of more than 200 mutations that affect beta-globin gene expression within the hemoglobin molecule, and it is one of the most common forms of congenital hemolytic anemia manifesting just after the first few months of life. ${ }^{1}$ It is usually characterized by an overall reduction in hemoglobin synthesis with ineffective erythropoiesis and hemolysis of mature cells and a massive decrease in mature red blood cell production. Ineffective erythropoiesis leads to skeletal and non-skeletal manifestations ${ }^{2,3}$ with extramedullary hematopoiesis and extreme expansion of marrow spaces in the long bones, spine, skull, ribs and facial bones ${ }^{2-4}$ resulting in the characteristic oro-facial features of prominent maxilla, retruded mandible, class II malocclusion, wide overjet and deep overbite leading to the socalled chipmunk facies. 5,6

Caries index is high in $\beta$-thalassemia major children and their oral health is poor as low priority is given to their oral health which in turn leads to further deterioration of systemic health due to poor masticatory function and the inability to eat and chew food properly. ${ }^{7}$ Poor oral health also affects the quality of life of children with $\beta$ thalassemia major. They experience mental fatigue, and decreased self-esteem, learning and social relationships. ${ }^{8-11}$ Over the past 20 years, the medical management of $\beta$-thalassemia major patients has improved enough to expect almost normal life expectancy, so the provision of integral rather than palliative dental treatment should be considered ${ }^{12}$. Many studies ${ }^{4-7}$ have described the prevalence, orofacial features and caries prevalence in children with $\beta$-thalassemia major but few have evaluated success and failure of dental intervention or compared types of dental interventions in these patients.

The null hypothesis of this study was that there is no difference in the success rate between MTA pulpotomy and indirect pulp capping in children with $\beta$-thalassemia major. The aim of the study was to compare between both types of vital pulp therapy in these children.

\section{METHODS}

\section{Study Design and Ethics}

Ethics approval was obtained from the Ethical Committee of the Faculty of Dentistry, Ain Shams University and Medical Research Ethics Committee of the National Research Centre. The proposal has the ethical approval ID number (PED)-17-3D meeting ID 68 at Faculty of Dentistry, Ain Shams University. Informed consent and assent were obtained from all patients and their parents. This randomized clinical trial study adhered to the Consolidated Standards of Reporting Trials (CONSORT) guidelines. The confidentiality of all data was preserved.

Power analysis was designed to have adequate power to apply a two-sided statistical test of the null hypothesis that there is no difference between the tested groups. By adopting an alpha level of (0.05) a beta of (0.2) i.e., power $=80 \%$ and an effect size (h) of (0.746) the predicted sample size (n) was a total of 60 . Sample size calculation was performed using $G *$ Power version 3.1.9.7. Therefore, sixty-five children with $\beta$-thalassemia major with having carious primary molars were randomly selected. Randomization was done using statistical analysis software (SPSS, Inc.; Chicago, IL) where patients were assigned to a number starting from (1) to (65) and randomly allocated to the studied groups (i.e. 30 in group (I) and 35 in group (II)) following a simple randomization procedure.

Medical history and medical consultation from the hematologist before treatment, proper coagulation profile (bleeding time) and hemoglobin levels were checked before starting any dental procedure. In children receiving blood transfusions, the dental treatment was carried out after 2-3 weeks of blood transfusion (when blood test results were optimal). Dental histories were also taken before treatment. Clinical photographs and periapical radiographs (Skydent, E-speed film, $2 \times 3 \mathrm{~cm}$, size $0,7 / 8 \times 13 / 8$ in) using the paralleling technique were also taken prior to and after treatment. Eligibility criteria of patients were as follows: (i) Children with $\beta$-thalassemia majör, (ii) age range of 4-7 years, (iii) clinically fit and well to receive dental treatment (with optimum blood test 
results), (iv) no associated or other superimposed systemic disorders.

\section{Inclusion criteria}

The inclusion and exclusion criteria were based on the American Academy of Pediatric Dentistry (AAPD) guidelines for vital pulp therapy in primary and young permanent teeth. ${ }^{13}$

Clinical inclusion criteria were as follow: (i) deep carious teeth, (ii) teeth diagnosed from clinical history as reversible pulpitis, (iii) absence of soft tissue swellings, (iv) absence of sinus or fistula, (v) restorable with filling or crown.

Radiographic inclusion criteria were as follow: (i) absence of periapical or furcation involvement, (ii) absence of widening of periodontal ligament space, (iii) no internal or external resorption.

Exclusion criteria of teeth were as follow: (i) nonvital teeth, (ii) symtomatic teeth with preoperative spontaneous pain, (iii) persistent pain and bleeding after hemostasis in cases of selected teeth for pulpotomy, (iv) children who could not continue the treatment or follow up.

All the dental procedures were carried out using a rubber dam (Sanctuary Dental Dam, medium, $5 " \times 5$ ", plain blue, Malaysia) to guarantee the success of vital pulp therapy following the American Academy of Endodontists. ${ }^{14}$ The children (patients) were divided into two groups: Group I $(n=30)$ received mineral trioxide aggregate pulpotomy (MTA plus, Cerkamed, Stalowa Wola, Poland) and Group II $(n=35)$ received indirect pulp capping (IPC) with high viscosity glass ionomer cement (Equia fil, GC, Tokyo, Japan)

\section{Study Protocol}

\section{Group I: MTA pulpotomy}

Preoperative clinical photos and radiographs were taken prior to treatment and local anesthesia was administered. Rubber dam (Sanctuary Dental Dam, medium, $5 \times 5$, plain blue, Malaysia) was placed for isolation and moisture control. Caries removal and de-roofing of the pulp chamber was done using round diamond burs (W\&H Diamond Burs, Australia). Bleeding was stopped using cotton pellets until there was no bleeding form the orifices of the pulp chamber. On a sterile glass slab, the contents of one bottle of MTA (MTA plus, plus, Cerkamed, Stalowa Wola, Poland) and one drop of distilled water were applied with a standard powder to distilled water ratio 3:1 as per manufacturer's instructions. A spatula was used to mix MTA as the powder and distilled water were mixed for 30 seconds to achieve a homogeneous consistency similar to wet sand. The mixture was then applied with an amalgam carrier and condensed to the cavity with a suitable sized condenser. The cavity was finally sealed with a final restoration as stainless steel crowns.

\section{Group II: Indirect pulp capping}

Preoperative clinical photos and radiographs were taken prior to treatment and local anesthesia was administered. Rubber dam was placed for isolation and moisture control. Selective dentin caries removal was conducted, removing infected dentin from the pulp wall and total removal from the surrounding walls using excavator (Zeffiro \#1, stainless steel excavator, Lascod, Italy) compatible with cavity size. Preconditioning of the surface with polyacrylic acid (Dentin Conditioner, GC corporation, Tokyo Japan) for ten seconds followed by washing and drying of the cavity. High viscosity glass ionomer cement (Equea; GC, Tokyo, Japan) was used and mixed according to manufacturer's instructions and then inserted into the cavity. Superficial protection of the restoration with a coat (Equia coat, GC corporation, Tokyo, Japan) that was cured for ten seconds for surface protection of the restoration

Clinical and radiographic follow ups were done at baseline and after 6 months and after one year. The clinical and radiographic evaluation criteria complied with the guidelines of the AAPD on vital pulp therapy in primary and young permanent teeth ${ }^{13}$ and the timing of the radiographic follow up complied with the guidelines of the AAPD on radiographic prescription for children, adolescents and individuals with special health care needs ${ }^{15}$ where failure is satisfying the criteria and success is not.

\section{Clinical Successful Evaluation Criteria}

Clinical success criteria included: asymptomatic teeth (absence of pain), absence of soft tissue swelling, absence of sinus or fistula and absence of tooth mobility.

\section{Radiographic Successful Evaluation Criteria}

Radiographic success criteria included: the absence of periapical or furcation involvement, 
the absence of widening of periodontal ligament space, and the absence of internal or external resorption. At the end of the study, the patients who had received both types of treatment were selected to provide their preferences of treatment type.

\section{Statistical Analysis}

Data were collected, revised, coded and entered into the Statistical Package for Social Science (SPSS, Inc.; Chicago, IL) version 23. The quantitative data were presented as mean, standard deviations and ranges when parametric and qualitative variables were presented as numbers and percentages. The comparison between the groups with qualitative data was done using a Chi-square test. Success (0) was the absence of the aforementioned criteria and failure (1) was their presence. The comparison between groups with quantitative data and a parametric distribution used an independent t-test.
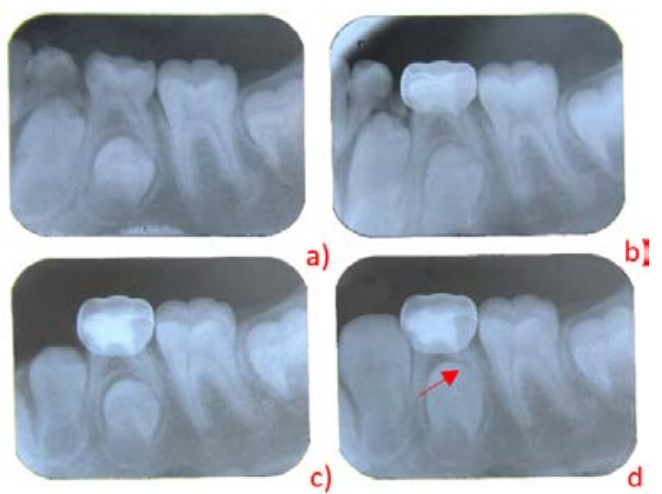

Figure 1. Radiographic follow up in MTA pulpotomy Group. a) preoperative; b) postoperative at baseline; b) after 6 months and d) after 1year with the red arrow showing normal physiological root resorption
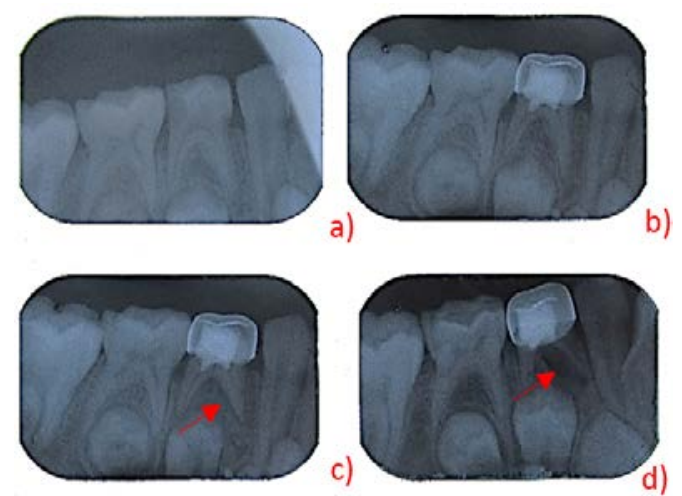

Figure 2. Radiographic follow up in MTA pulpotomy Group. a) preoperative; b) postoperative at baseline; c) after 6 months with red arrow showing wideninng of periodontal ligament space the beginning of root resorption and d) after 1year with the red arrow space and external root resorption radiographically
The confidence interval was set to $95 \%$ and the margin of error accepted was $5 \%$ and $p$-value $<0.05$ considered significant.

\section{RESULTS}

The study included 65 children with $\beta$ Thalassemia major with a mean age range of 5.77 \pm 0.96. While Figure 1 shows a representative radiographical follow-up and normal physiological root resorption in a tooth after one year in Group I, MTA pulpotomy, Figure 2 shows increased widening of periodontal ligament space and external root resorption in one year follow-up. While Figure 3 and 4 show representative radiographical follow-up and normal physiological root resorption after one year in Group II, IDP. Tables 1 and 2, and Figure 5 show the success and failure comparative rates. Figure 6 shows patients' preference of type of treatment received.

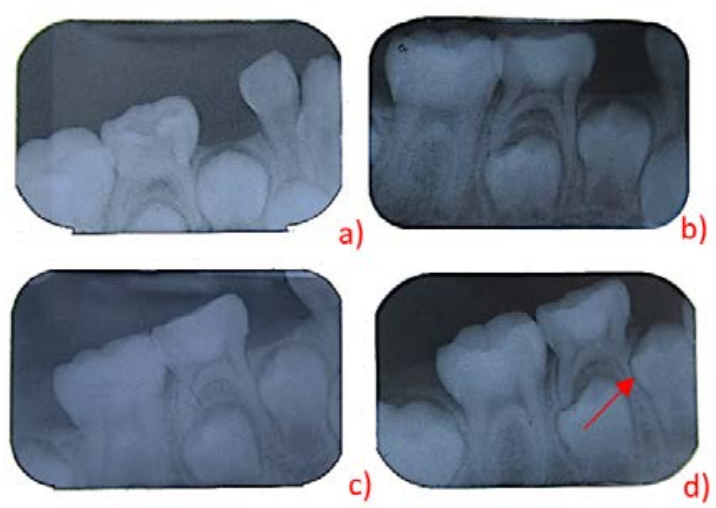

Figure 3. Radiographic follow up in indirect pulp capping (Group II): a) preoperative; b) at baseline; b) after 6 months; and d) after 1 year with red arrow showing normal physiological root resorption and the beginning of eruption of lower permanent first premolar

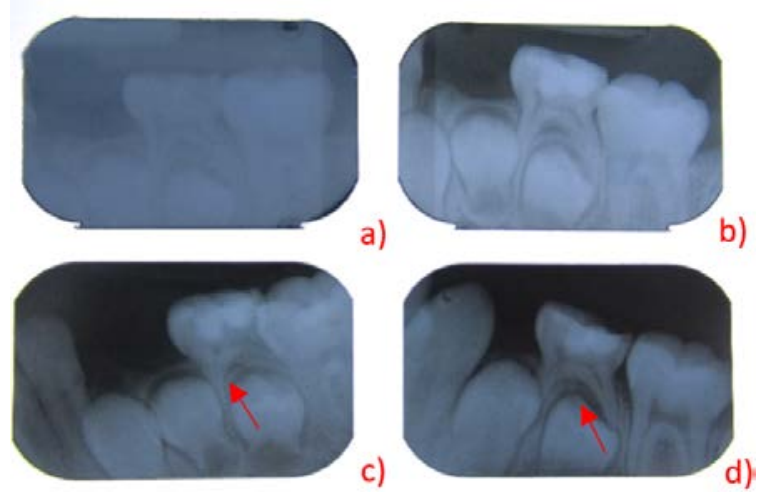

Figure 4. Radiographic follow up in indirect pulp capping (Group II): a) preoperative; b) postoperative at baseline; b) after 6 months and d) after 1 year also with red arrows showing normal physiological resorption 
Table 1. Clinical success rates in mineral trioxide aggregate pulpotomy (Group I) and indirect pulp capping (Group II)

\begin{tabular}{crrr}
\multicolumn{2}{c}{ Group I $(\mathrm{n}=30)$} & \multicolumn{2}{c}{ Group II $(\mathrm{n}=35)$} \\
Success & Failure & Success & Failure
\end{tabular}

\begin{tabular}{lccccccccc} 
& $\mathrm{n}$ & $\%$ & $\mathrm{n}$ & $\%$ & $\mathrm{n}$ & $\%$ & $\mathrm{n}$ & $\%$ & \\
\hline Baseline & 30 & 100 & 0 & 0 & 35 & 100 & 0 & 0 & - \\
6 months & 27 & 90 & 3 & 10 & 35 & 100 & 0 & 0 & 0.055 \\
1 year & 27 & 90 & 3 & 10 & 35 & 100 & 0 & 0 & 0.055 \\
\hline
\end{tabular}

Table 2. Radiographic success rates in Mineral Trioxide Aggregate Pulpotmy (Group I) and Indirect Pulp Capping (Group II)

\begin{tabular}{lccccccccc}
\hline & \multicolumn{3}{c}{ Group I $(\mathrm{n}=30)$} & \multicolumn{3}{c}{ Group II (n=35) } & \multicolumn{2}{c}{$\mathrm{p}$-value } \\
& $\mathrm{n}$ & $\%$ & $\mathrm{n}$ & $\%$ & $\mathrm{n}$ & $\%$ & $\mathrm{n}$ & $\%$ & \\
\hline Baseline & 30 & 100 & 0 & 0 & 35 & 100 & 0 & 0 & - \\
6 months & 27 & 90 & 3 & 10 & 35 & 100 & 0 & 0 & 0.055 \\
1 year & 27 & 90 & 3 & 10 & 35 & 100 & 0 & 0 & 0.055 \\
\hline
\end{tabular}

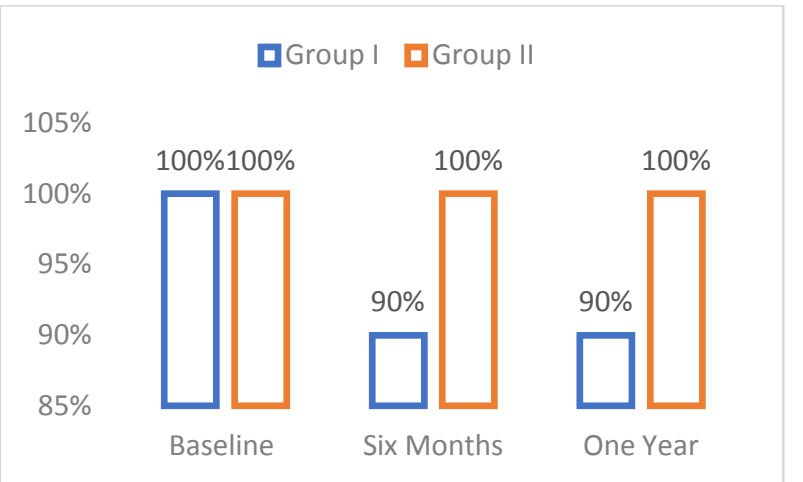

Figure 5. Radiographic success rates in Group I and II

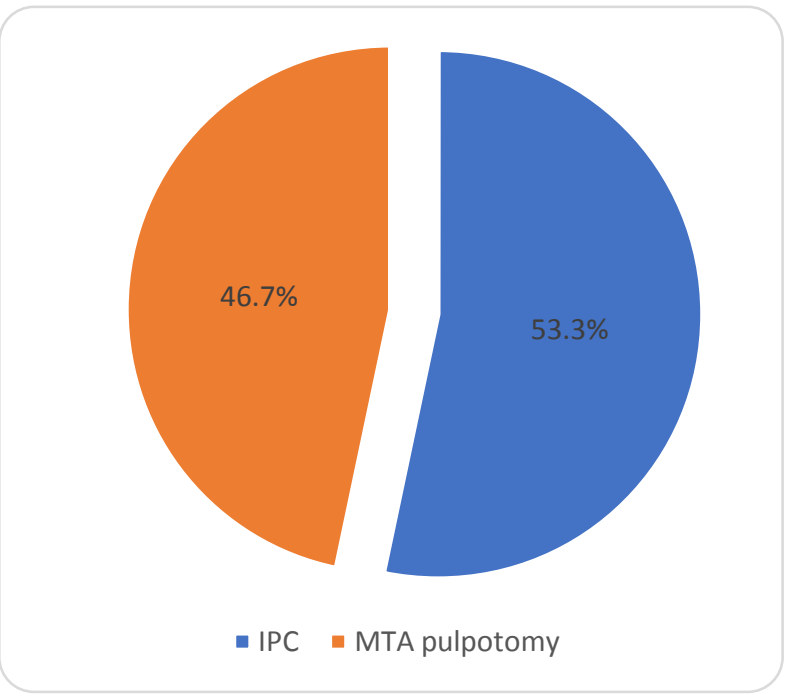

Figure 6. Percentage of patient preferences

\section{DISCUSSION}

Managing carious primary teeth is a challenge for the pediatric dentist. ${ }^{13,16,17}$ In children with $\beta$ thalassemia major, successful management and outcome depend on evaluating each patient's medical and dental history to determine the best treatment for their age ${ }^{12}$ and accurately diagnosing the status of the pulp prior to therapy. ${ }^{16}$ If the dental pulp is vital or reversibly inflamed, vital pulp therapy techniques are appropriate. ${ }^{17-19}$

In deciduous dentition, pulpotomy is the procedure of choice to remove infected, inflamed pulp tissue, and it is usually performed after a pulpal exposure whether carious or mechanical. It allows the preservation of teeth that otherwise would be planned for extraction and it helps maintain the arch integrity. $13,18,19$

Formocresol has been the most popular pulp dressing material for pulpotomized primary molars for many years. However, its use has decreased considerably worldwide. ${ }^{20,21}$ The longterm evaluation of MTA when used as the primary molar medication in pulpotomies, has a high success rate. ${ }^{22}$ MTA also has no systemic or local toxic side effects. ${ }^{20,21}$ and has proven therapeutic properties in various endodontic procedures in primary teeth. ${ }^{20,21,23}$

In this study, the clinical and radiographic success rates were both $90 \%$ after six months and after one year in cases treated with MTA pulpotomy in Group I without further clinical or 
radiological pathological complications. Other studies $20,24,25$ have had similar clinical and radiographic MTA success rates of $94-100 \%$. This may be due to dentinal bridge formation at the orifice entrance and the preservation of the vitality of the remaining pulp tissue due to its biocompatibility. ${ }^{20}$

In this study the treated teeth with MTA pulpotomy were free of any pathological clinical symptoms or radiographic pathology except for $10 \%$ of the treated teeth which showed radiographical alterations as external root resorption. These findings were the same as in a previous study 22 which reported radiographical internal resorption due to undiagnosed chronic inflammation within the radicular pulp prior to pulp therapy.

Pulpotomy accompanies presence of alterations as faster root resorption and early loss. ${ }^{26-28}$ Therefore, primary tooth pulpotomies should be radiographically evaluated at least annually because the success rate of pulpotomies diminishes over time. ${ }^{15,21,24}$

IPC is best in the case of deep carious lesion without pulp involvement. Two possible treatment options for IPC exist: total and the selective caries removal techniques. The latter avoids greater damage to the tooth and avoids pulp exposure. ${ }^{2930}$ IPC is more conservative than pulpotomy because it preserves the vitality of coronal and radicular pulp. ${ }^{31}$

IPC relies on the selective removal of caries. ${ }^{31-}$ 33 The dentin left in place is thereafter covered with a medicament followed by a final restoration. After sealing the cavity, the remaining dentine is capable of remineralization due to changes in the microenvironment caused by the lack of substrates for the bacteria and the caries process is arrested. ${ }^{34,35}$ This technique which is based on minimally invasive procedures is favored in current practice for caries treatment, 35,36 and it is time-saving and requires less discomfort particularly in $\beta$-thalassemic patients.

In this study, the success rate of IPC was $100 \%$ after six months and after one year. The teeth treated with IPC were free of any clinical or radiographic signs or symptoms. Similarly, a study by Vidya et al. ${ }^{22}$ reported a $100 \%$ success rate in cases treated with IPT. ${ }^{22}$ Other studies ${ }^{37,38,39}$ reported a success rate greater than 90\% IPC success rate and considered it a required pulp therapy procedure.

The current study showed that both MTA pulpotomy and IPC are effective pulp therapy techniques for primary teeth in $\beta$-thalassemic patients. Vidya et al. ${ }^{22}$ also studied the success rates of IPC and pulpotomy in the treatment of deep carious lesions in primary molars, and they reported high success rates in both groups with statistically non-significant difference. ${ }^{22}$ Faugeron et $\mathrm{al}^{31}$ reported greater long-term success (three years) with IPC than pulpotomy for treating deep carious lesions in primary teeth.

At the end of the study, patients who had received both types of treatment were asked to provide their overall satisfaction and preference of the treatment type on a scale of satisfaction from 1-5. The patient preference was higher for IPC $(53.3 \%)$ than vital pulpotomy (46.6\%) considering the treatment duration, comfort, cost, and postoperative satisfaction. Ricketts et al ${ }^{39}$ concluded that IPC is a more conservative, time saving approach the requires less discomfort to the patient. Likewise, Vidya et $\mathrm{a}^{22}$ found that IPC required less chair side time, increased child cooperation and was more cost effective

One of the limitations of this study is the transfusion schedule of the patients which increased the time taken to finish the study. The present study has also the limitations of the far destinations, non-compliance and patient drop outs due to the medical condition. Another limitation is related to the cost of material taking into account the time of survival of the primary tooth in the oral cavity.

In children with in $\beta$-thalassemia major, both vital pulp therapy techniques (MTA pulpotomy and IPC) are applicable but IPC is preferred and more conservative requiring less effort and time by both the patient and dentist.

\section{CONCLUSIONS}

Children with $\beta$-thalassemia major have a higher caries index than healthy children which is attributable to inadequate dental care and the poor accessibility of dental health services due to their medical condition. MTA placed on 
amputated pulpal tissue preserves the pulp vitality and promotes the regeneration of hard tissues, and IPC is a conservative procedure that treats deep carious lesions on teeth with no signs of pulp exposure or symptoms of pulp degeneration. Both techniques are equally successful in treating primary carious molars in $\beta$-thalassemic children but IPC is more preferred because it is the less invasive and involves less effort, fatigue, and time.

\section{REFERENCES}

1. El-Kamah GY, Hosny LA, Sobh KS. Exploring Phenotypic Alterations in Response to High Hemoglobin F Level in Egyptian beta Thalassemia Patients. J Appl Sci Res 2009;5:15471551

2. Bayrak S, Bulut DG, Orhan K, Sinanoglu EA, Çakmak EŞK, Misirli M, et al. Evaluation of Osseous Changes in Dental Panoramic Radiography of Thalassemia Patients Using. Mandibular Indexes and Fractal Size Analysis. Oral Radiol 2020;36:18-24

3. Zhu G, Wu X, Zhang X, Wu M, Zeng Q, Li $\mathrm{X}$. Clinical And Imaging Findings In Thalassemia Patients With Extramedullary Hematopoiesis. Clinic Imaging 2012; 36:475-482

4. Bouguila J, Besbes G, Kochtali H. Skeletal Facial Deformity in Patients With $\beta$-Thalassemia Major: Report of One Tunisian Case and a Review of the Literature. Int J Pediatr Otorhinol 2015;79:1955-1958

5. Al- Raeesi S, Kowash M, Hassan A, Al- Halabi M. Oral Manifestations and Dentofacial Anomalies in B-Thalassemia Major Children in Dubai (UAE). Spec Care Dent 2018;38:25-30

6. Javid B, Al-Naief S. Craniofacial Manifestations of B-Thalassemia Major. Oral Surg, Oral Med, Oral Pathol and Oral Radiol 2015;119:33-40

7. Arora M, Nayeemuddin SM, Ghatak S, Singh B. Growth Impairment and Dental Caries in Thalassemia Major Patients. Indian J. Clinic Anatomy and Physiol 2014;1:15-21

8. Adham S, Afifi H, Thomas M, Magdy P, ElKamah G. Quality of Life Outcomes In A Pediatric Thalassemia In Egypt. Int J Hemo Res 2017;41:16-20
9. Alalfy MS, Farid MN, Labib JH and Rezkallah H. Quality of life of Egyptian B-Thalassemia Major Children and Adolescents. Egyptian J Haematol 2014;39:222-226

10. Amirabadi F, Saravani S, Miri-Aliabad G, Khorashadi-Zadeh M. The Association Between Dental Health Status And Oral Health-Related Quality Of Life In Children Diagnosed With BThalassemia Major In Zahedan City, Iran. Int J Pediatr 2019; 7:8985-8991

11. Madmoli Y, Madmoli M, Davoodi N, Niksefat M, Saberipour B, Darabiyan P, et al. Health Related Quality Of Life In Patients With BThalassemia Major in Northern Khuzestan Province, Southwest of Iran in 2015-2016. J Res Med Dent Sci 2019;7:164-169

12. Labrini F, Oubenyahya H. Dental Management of Beta Thalassemia Major Patients: A Review. Int J Med and Health Res 2018;4:1-5

13. American Academy of Pediatric Dentistry (AAPD). Guideline on Pulp Therapy for Primary and Immature Permanent Teeth. Pediatr Dent 2016;17:280-288

14. American Academy of Endodontists. Policy statement on the use of Dental Dams. [Internet] [cited 2017 Oct 20]. Available from: https://www.aae.org/specialty/wp-

content/uploads/sites/2/2017/06/dentaldamstat ement.pdf

15. AAPD Reference Manual 2018/19. Guidelines on Radiographic Prescription for Children, Adolescents and Individuals with Special Health Care Needs. Pediatr Dent 2019;40:213-215

16. Zakaria N. Saving the Pulp and Essential Issues in Pulp-Capping Treatment. J Dentofac Sci 2016;1:73-76

17. Fuks B, Guelmann M, Kupietzky A. Current Developments in Pulp Therapy for Primary Teeth. Endod Topics 2012;23:50-72

18. Fuks B, Hebling J, De Souza A, Costa A. The Primary Pulp: Development And Biomedical Background.In: Fuks B, Peretz B. Editors. Current Concepts in Vital Pulp Therapy for Primary and Young Permanent Teeth. Pediatric Endodontics 2016. p. 8-21

19. Fuks AB, Kupietzky ARI, Guelmann M. Pulp Therapy for The Primary Dentition. In: Nowak AJ, Christensen JR, Mabry TR, Townsend JA, Wells MH. editors. Pediatric Dentistry Infancy 
through Adolescence. USA: Elsevier; 2019. p.337338

20. Jan I, Shah FA, Ali A, Zain M, Afridi R, Khan AM, et al. Efficacy of Formocresol and Mineral Trioxide Aggregate Pulpotomy among Primary Molars: A Randomized Control Trial. Pakistan Oral Dent J 2019;39:289-292

21. Basak F, Akgun OM, Polat GG, Altun C. Clinical and Radiographic Evaluation of the Effectiveness of Formocresol, Mineral Trioxide Aggregate, Portland Cement, And Enamel Matrix Derivative In Primary Teeth Pulpotomies: A Two Year Follow-Up. J Clin Pediatr Dent 2016; 40:1420

22. Vidya KB, Patil SB, Anegundi RT. Is Pulpotomy Obsolete? A Clinical Study on the Success Rates Of Indirect Pulp Capping and Pulpotomy in the Treatment of Deep Dentinal Caries in Primary Second Molars. J Int Clinic Dent Res Or 2015;7:24-28

23. Da Rosa LO, Cocco AR, Silva TM, Mesquita LC, Galarca AD, Silva AF, et al. Current Trends and Future Perspectives of Dental Pulp Capping Materials: A Systematic Review. J Biomed Mat Res B: Appl Biomat 2018;106:1358-1368

24. Jenqueira MA, Cunha NN, Caixeta FF, Marques NCT, Oliveira TM, Moretti ABS, et al. Clinical, Radiographic and Histological Evaluation of Primary Teeth Pulpotomy Using MTA and Ferric Sulfate. Brazilian Dent J 2018;29:159-165.

25. Godhi B, Tyagi R. Success Rate of MTA Pulpotomy on Vital Pulp of Primary Molars: A 3 Year Observational Study. Int J Clinic Pediatr Dent 2016; 9:222-227

26. Fuks AB. Vital Pulp Therapy with New Materials for Primary Teeth: New Directions and Treatment Perspectives. Pediatr Dent 2008;30:211-219

27. Oliveira TM, Moretti AB, Sakai VT, Lourenço Neto N, Santos CF, Machado MA, Abdo RC. Clinical, Radiographic and Histologic Analysis of the Effects of Pulp Capping Materials Used In Pulpotomies of Human Primary Teeth. Eur Arch Paediatr Dent 2013;14:65-71

28. Mello B, Stafuzza TC,Vitor L, Rios D,Silva T,Machado M, et al. Evaluation of Dentine Pulp Complex Response after Conservative Clinical Procedures in Primary Teeth. Int J Clinic Pediatr Dent 2018;11:188-192
29. Stafuzza TC, Vitor LLR, Rios D, Silva T, Machado AM and Marchini T. Clinical and Radiographic Success of Selective Caries Removal to Firm Dentin in Primary Teeth: 18-Month Follow-Up. Case Rep Dent 2018:1;1-4

30. Schwendicke F, Paris S, Tu YK. Effects of Using Different Criteria for Caries Removal: A Systematic Review and Network Meta-Analysis. J Dent 2015;43:1-15

31. Faugeron VS, Porot A, Bolla MM, Courson F. Indirect Pulp Capping Versus Pulpotomy For Treating Deep Carious Lesions Approaching The Pulp In Primary Teeth: A Systematic Review. Eur J Paediatr Dent 2016;17:107-112

32. Banerjee A. Minimal Intervention Dentistry: Part 7. Minimally Invasive Operative Caries Management: Rationale and Techniques. British Dent J 2013;214:107-111

33. Freitas MF, Santos J, Fuks A, Bezerra A, Azevedo T. Minimal Intervention Dentistry Procedures: A Ten year Retrospective Study. J Clin Pediatr Dent. 2014;39:64-67

34. Petrou MA, Alhamoui FA, Welk A, Altarabulsi MB, Alkilzy MH, Splieth C. A Randomized Clinical Trial on the Use of Medical Portland Cement, MTA and Calcium Hydroxide in Indirect Pulp Treatment. Clinic Oral Invest 2013;18:1383-1389

35. Franzon R, Guimaraes LF, Magalhaes CE, Haas AN, Araujo FB. Outcomes Of One-Step Incomplete And Complete Excavation In Primary Teeth: A 24-Month Randomized Controlled Trial. Caries Res 2014;48:376-383

36. Chauhan A, Dua P, Saini S, Mangla R, Butail, Ahluwalia S. In Vivo Outcomes of Indirect Pulp Capping In Primary Posterior Teeth: A 6 Months Follow-Up. Contemp Clinic Dent 2018; 9:69-73

37. Al-Zayer MA, Straffon LH, Feigal RJ, Welch KB. Indirect Pulp Treatment of Primary Posterior Teeth: A Retrospective Study. Pediatr Dent 2003;25:29-36

38. Vij R, Coll JA, Shelton P, Farooq NS. Caries control and other variables associated with success of primary molar vital pulp therapy. Pediatr Dent 2004;26:214-220

39. Falster CA, Araújo FB, Straffon LH, Nör JE. Indirect pulp treatment: in vivo outcomes of an adhesive resin system versus calcium hydroxide for protection of the dentin-pulp complex. Pediatr Dent 2002;24:241-2448 
40. Ricketts D, Lamont T, Innes NPT, Kidd E, Clarkson E. Operative caries management in adults and children. Cochrane Database Syst Rev 2013;28:CD003808

\section{How to cite this article:}

Leila Mounir El. Gibaly, Mohamed Zayed Radwan, Amr Mahmoud Abdel-Aziz, Ghada Yousef El. Kamah. Comparison of Two Vital Pulp Therapies In $\beta$-Thalassemic Children. Contemp Pediatr Dent 2020:1(1):33-41.

\section{Declarations}

Acknowledgements: Our deepest gratitude and appreciation goes to Prof. Dr. Amr Mahmoud Abdel-Aziq, Professor in Pediatric Dentistry and Dental Public Health Department, Ain Shams University for his supervision, continuous effort, sincere advice and valuable guidance. Our deepest thanks and appreciation also goes to Prof. Dr. Ghada Yousef El.Kamah, Professor in Clinical Genetics Department, Human Genetics and Genome Research Division, National Research Centre for her great support, experience and guidance. Our special thanks goes to Dr. Mohamed Zayed Radwan, lecturer in Pediatric Dentistry and Dental Public Health Department, Ain Shams University for his sincere cooperation and effort and his continuous support. Also our thanks goes to Dr.Maha Rashed Abouzaid, researcher in Oro-dental Genetics Department, Human Genetics and Genome Research Division, National Research Centre for her hard work, great help and patience. Finally, all thanks goes to the patients and their parents who participated in this study for their willingness to participate in this study and their patience because without their cooperation, this study wouldn't have been possible.

Conflict of Interest Statement: The authors disclose no potential conflicts of interest.

Ethics Statement: Ethics approval was obtained from the Ethical Committee of the Faculty of Dentistry, Ain Shams University and Medical Research Ethics Committee of the National Research Centre (approval ID number PED-17-3D).

Informed Consent: Written consent was taken for participation of both parents and children in the study.

Author contributions: Conception and design: All Authors; Acquisition of data: LMEG, AMAA, GYEK; Interpretation of data: LMEG, MZR, GYEK; Drafting article: LMEG, MZR,; Revision artice: LMEG, MZR, AMAA, GYEK; Final approval: All Authors

Funding: This work is not finantiated.

Data Availability: The data used to support the findings of this study can be made available upon request to the corresponding author.

Peer-review: Externally double-blinded peer-reviewed. 